\title{
Study on Food Quality and Safety Issues and Total Quality Management of Food Production
}

\author{
Mei Li \\ Guangxi Vocational College of Technology and Business, Nanning, Guangxi, 530008, China
}

Key words: Quality management; Food safety; Total quality management; PDCA

Abstract: Along with the development of society, the concern degree of people to the food quality safety is more and more high and the food profession has to adapting to this kind of development trend and constantly strengthens own orientation ability and competition ability in order to exist and develop much strongly. Therefore, detailed analysis of the status of China's food quality and safety, summarizing the reasons of many food safety problems, and to develop a comprehensive quality management measures in line with China's actual situation, so as to guarantee the quality and safety of our food. The paper proposed the TQM based on PDCA cycle, the new food quality management system has the advantages of high management level, and it also meets the management requirements of modern enterprises. Total quality management can achieve the sustainable development of enterprises through customer satisfaction, so that the entire management system can be a whole and rise to a strategic height. The countermeasures of food safety quality control also proposed in the paper.

\section{Introduction}

At present, food safety has become the focus of attention of our society; food safety not only has a direct impact on people's health, but also become a key factor in social stability and economic development ${ }^{[1-2]}$. But with the development of market economy, in order to pursue their own interests driven by the interests, some manufacturers become to produce the foods that harm people's health food. These food quality and safety problems occur frequently, so that the lives and health of the whole nation has been a great threat. There are many factors that cause the food quality and safety problems, like natural factors, artificial factors, not only with their own moral and related businesses, and the relevant quality supervision department is closely linked to poor management.

In order to improve the level of food quality management, there are many measures applied to the food quality management. Especially, in 1960s, the application of total quality management (TQM) makes the quality management from low level to a higher level. TQM means an organization that is based on quality, whose aim of achieving long-term success through customer satisfaction and all members of the organization and the community ${ }^{[3-4]}$. The core idea of TQM is customer first, and Lawrence suggests that enterprises should pay more attention to the customers when the uncertainty of external environment is very large, it is the best performance of customer-oriented. Narver's research shows that customer orientation is significantly related to corporate profitability. For the food industry, the customer first appears more important, if you can not let the customer uppermost in this enterprise, then the food safety issues will always be a key factor in the development of enterprises.

The paper proposed the TQM based on Plan-Do-Check-Action (PDCA) cycle, the new food quality management system has the advantages of high management level, and it also meets the management requirements of modern enterprises. Total quality management can achieve the sustainable development of enterprises through customer satisfaction, so that the entire management system can be a whole and rise to a strategic height. The countermeasures of food safety quality control also proposed in the paper.

\section{Structure and composition of food safety management system}

The objectives of the food management system are: firstly, the management should promptly prevent food borne diseases, and protect public health; Secondly, through the elimination of misleading tendency of food, unsanitary, and even toxic and harmful food into the public, in order to 
protect the interests of consumers; Thirdly, establish enterprise standard quality system that is in line with the international standards to maintain the consumer's confidence in the production of food safety, so as to further promote the development of the company. The food management system should cover all food production, processing and logistics, sales and after-sales processes, and it must be enforced ${ }^{[5]}$.

Food quality safety management system mainly consists of five parts: the quality standards of food; food quality management; Quality Supervision Inspection and laboratory testing of food; information, education, communication and training of food quality. The structure of food management system is shown in the Figure 1.

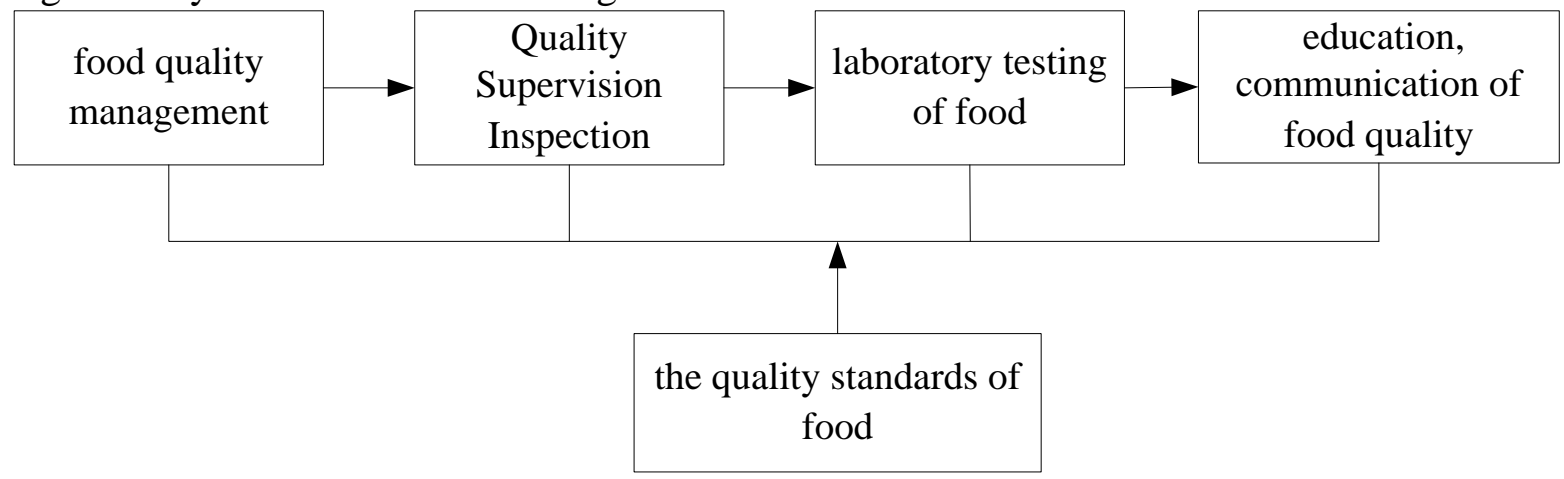

Fig 1 the structure of food quality management system

As we can see from the Figure 1, the quality standards of food are the foundation of the food quality management system. The national food regulations are the guiding unit of enterprise product system. Modern food laws and regulations is not only in order to ensure the effectiveness of food safety law, but also the enterprise product quality and safety management should be strictly in accordance with the law to establish a system of preventive protection. To this end, in addition to food laws and regulations, food companies need to update product standards. The integration of a number of standards of food quality can perfect the food safety objectives. Enterprises should actively learn and absorb advanced peer formulated successful practices in terms of food quality and safety standards, and combined with the characteristics of the enterprises of the relevant information, the concept and requirement of amending, the introduction to this enterprise the quality standard system. The other parts of food management system are based on the standards of food quality, and given the length of the reasons; the paper does not expressed in detail.

\section{The total quality management and application of food quality}

\subsection{PDCA cycle}

PDCA cycle is the cycle of quality management, it is proposed in1950s, and it also called the Deming-cycle ${ }^{[6]}$. In the actual management activities, in order to improve the management quality and management efficiency, the PDCA cycle implements the work of Plan, Do, Check and Action work. As we can see, the model of PDCA is shown $n$ the figure 2.

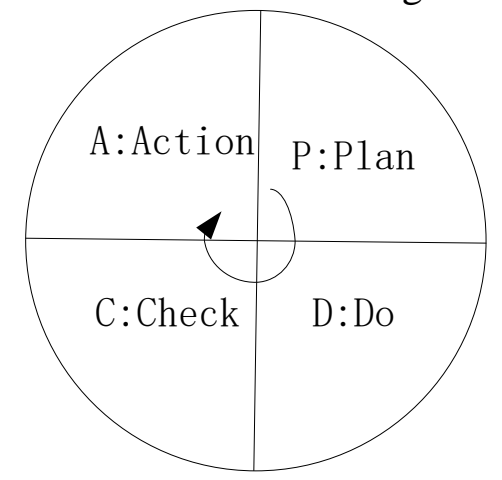

Fig 2 the model of PDCA cycle

PDCA cycle is a spiral rising process, each cycle will make the quality level and management level to improve a step, the step is called the adjustment period. The whole process of PDCA is shown 
in the figure 3. According the cycle process, the quality of management will improved in the every cycle, and setting the goal of cycle, the cycle will be endless.

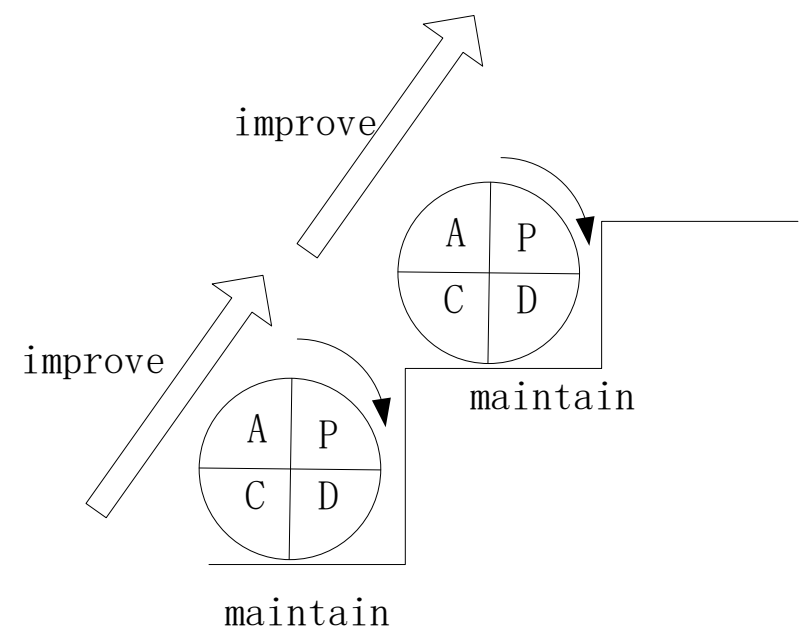

Fig 3 the cyclic improvement of PDCA cycle

\subsection{The total quality management model based on PDCA cycle}

In the process of the development of food quality management system, the organization plan and the overall implementation of the system quality control is very complex system engineering. In the food quality management system, PDCA cycle is a dynamic cycle, which can be carried out in each process of the organization or in the whole system. There is a close relationship between the process of the product realization and the planning and management of the quality management system in the other processes. The total quality management based on PDCA cycle is shown in the figure 4.

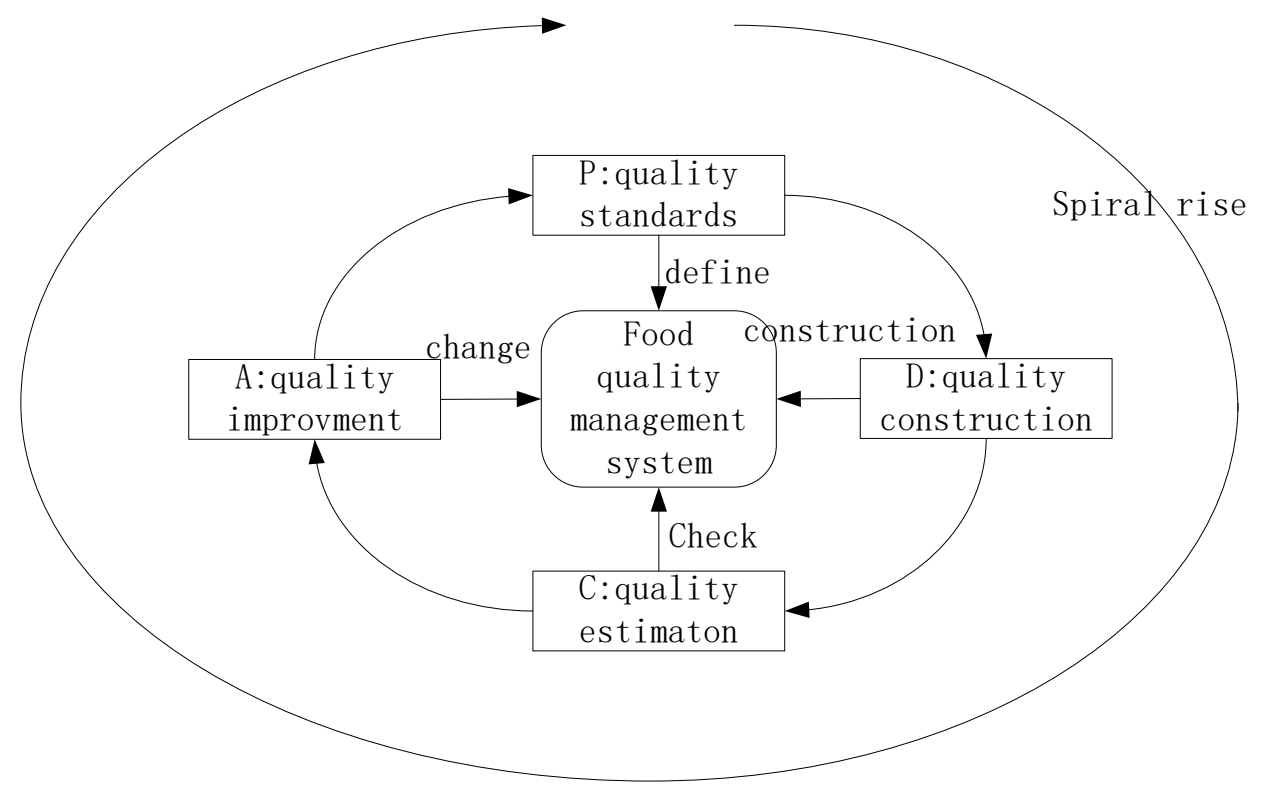

Fig 4 the total quality management based on PDCA cycle

This model is the PDCA cycle process about the food quality control problem.

At the first stage of cycle, we need to develop a plan for the quality, process, and resources needed for the development of the product, and it also clearly needs the objectives and standards.

At the second stage, according to the plan, a series of activities implement in the development activities, the quality is constructed into the product, but the defects become to be emerging. Especially, the development of quality information management system is a high density of intellectual activity, so the defects in this process are inevitable. 
At the third stage, by reviewing and testing the product, determining whether the plan is achieved and whether the target is completed. If the product and standard deviation, we need to locate the reasons for the deviation of the error.

At the last stage of PDCA cycle, dealing with the results of the check process. The successful experience can be affirmed and appropriate promotion, standardization. Lessons learned from failure experiences need to be taken seriously. And the problems of unresolved issues are introduced in the next cycle ${ }^{[7]}$.

\subsection{The countermeasures of food safety quality control}

In order to improve the quality of food safety, we build the above model of quality control system. Based on the total quality management model, the following countermeasures of food safety quality control can be proposed.

(1) At the plan stage, according to the food safety regulations and standards, we define the goal of food quality management. In order to realize the standards, the food technology research is the most important factors. Only in this way, can the enterprise gain the advantages in the markets competition and reduce the food fraud. It is the fundamental method of food safety control.

(2) At the stage of check, food production enterprises have to conduct food quality control and inspection. The detailed methods are as follows (1) preparing and implementing a special quality control process card; (2) filling in the quality records, a clear responsibility to ensure traceability; (3) strengthening food inspection and supervision; (4) strictly control the unqualified products, avoid secondary pollution. Through these ways, the PDCA cycle can be built, the improvement of food quality can get a spiral rise.

(3) At the stage of action, staff quality consciousness education and whole staff innovation also get the improvement. And the build of PDCA cycle, customer satisfaction, process optimization and improvement and self learning and progress also can be realized in the TQM model based on the PDCA cycle.

\section{Summary}

Compared with traditional management methods, the concept of total quality management in food production is more advanced, more scientific and more comprehensive. According to the tenet of "customer first", each production step is implemented. Specifically, under the drive of the market, the enterprise will try to meet customer needs and respond quickly to competitors. Customer-oriented means it is with full innovation as the driving force, so as to establish a market advantage, obtain stable earnings growth. It is not only the pursuit of quality, but through the establishment of a system and continuous improvement to achieve comprehensive performance improvement, which is to simultaneously achieve high quality, low cost, high productivity, fast speed, good social responsibility and so on.

Through the comprehensive quality management can not only in-depth understanding of the production process, but also get the entire food production process in each link of the feedback information. Because of the comprehensive information on the existence of more in-depth understanding of the problem, , so that enterprises will be able to have a high quality, low cost, strong competitiveness, good economic efficiency of the new situation.

\section{References}

[1] Boxstael S V, Habib I, Jacxsens L, et al. Food safety issues in fresh produce: Bacterial pathogens, viruses and pesticide residues indicated as major concerns by stakeholders in the fresh produce chain[J]. Food Control, 2013, 32(1):190-197.

[2] Chen C, Zhang J, Delaurentis T. Quality control in food supply chain management: An analytical model and case study of the adulterated milk incident in China[J]. International Journal of Production Economics, 2014, 152(6):188-199.

[3] Svensson M. TQM-based self-assessment in educational organizations : help or hindrance?[J]. Luleå Tekniska Universitet, 2016, 9(1):104-104.

[4] Nzewi H N, Chiekezie O M, Afunwa P, et al. Total Quality Management (TQM) and Business 
Performance: A Study of the Perception of Managers of Fast-Food Businesses in Awka Urban[J]. Social Science Electronic Publishing, 2015.

[5] Tomaševic' I, Šmigic', N, Đekic', I, et al. Evaluation of food safety management systems in Serbian dairy industry.[J]. Mljekarstvo, 2016, 66(1):48-58.

[6] Lei X. PDCA Cycle in the Disinfection Supply Center,the Application of Continuous Quality Improvement[J]. China Health Industry, 2015, 95(20):11834-11839.

[7] Liang W H, Huang F, Chen Y L. The application of PDCA cycle method in quality continuous improvement of surgical nursing[J]. Nursing Practice \& Research, 2016. 